\title{
Competencia de mercado e informalidad en el sector manufacturero mexicano 1987-2004'
}

\section{Product market competence and labor informality in the mexican manufacturing sector 1987-2004}

\author{
Eduardo Rodríguez-Oreggia* \\ MARTín LiMA** \\ David Mulato-Martínez ${ }^{* * *}$
}

\begin{abstract}
This paper relates informality, measured with access to social security benefits, in the mexican labor markets with product competence. Using microdata from labor surveys and industrial data, we performed a two-stage strategy, in which the first stage separates the industry informality differentials for workers, and in a second stage we pooled the data and estimated the effect from market competition on the labor market. Results show that competence can increase informality in the labor market.
\end{abstract}

Keywords: product market competition, informality, manufacturing, panel data, labor market.

\section{Resumen}

El presente estudio relaciona la competencia de mercado en productos con la informalidad laboral (acceso a seguridad social) en el sector manufacturero mexicano. Con microdatos provenientes de encuestas laborales 1987-2004 y de la encuesta industrial anual se lleva a cabo una estrategia en dos etapas: en la primera, separamos los diferenciales de informalidad de cada industria y, en la segunda, combinamos los datos en un panel para determinar el efecto mayor en la competencia de mercado. Los resultados muestran que la competencia puede incrementar la informalidad dado el actual marco institucional laboral.

Palabras clave: Competencia de mercado, informalidad, manufacturas, datos panel, mercado de trabajo.

\footnotetext{
${ }^{1}$ Los autores agradecen el financiamiento parcial del Consejo Nacional de Ciencia y Tecnología (Conacyt) y a Miguel Ángel de Jesús Vázquez.

* Escuela de Graduados en Administración Pública y Política Pública (Egap), Tecnológico de Monterrey, campus Estado de México, México. Correo-e: eduardo.oreggia@gmail.com

** CONEval. Correo-e: jmlimav@gmail.com

*** sFr. Correo-e: dmulato@gmail.com
} 


\section{Introducción}

Desde mediados de los noventa, México experimentó un aumento importante en las tasas de empleo informal, medido éste como trabajo con acceso al beneficio de seguridad social, hasta llegar a un porcentaje alrededor de $60 \%$ de todos los ocupados, esta cifra no ha disminuido desde entonces y se observa una gran movilidad entre los sectores cubiertos y no cubiertos por la seguridad social, lo que evidencia, en parte, el bajo costo de desplazarse entre éstos. (Rodríguez, 2009).

Las regulaciones laborales mexicanas son, en promedio, más costosas que en otros países y se imponen, adicionalmente, barreras a la contratación y al despido de trabajadores formales o cubiertos por la seguridad social. Por otra parte, existe un sistema fiscal complejo que favorece la informalidad, así como uno de protección social donde es más fácil obtener beneficios que en el caso de un sistema de cotizaciones a la seguridad social (Levy, 2008).

En este contexto, el presente estudio plantea analizar el efecto que puede tener una mayor competencia de mercado sobre la informalidad laboral en México. Nickell (1999) ya ha señalado que el mercado de trabajo es afectado de varias formas por la competencia de productos: en los niveles de empleo, en el aumento de la demanda de productos, derivada de una baja en precios reales; a través de mayores salarios reales producidos por la baja en el precio de productos, y por la captura de utilidades de algunos grupos, por ejemplo, los sindicatos que ejercen poder de decisión. De acuerdo con Amable y Gatti (2004 y 2006) también hay un efecto derivado de mayor competencia de mercado sobre trabajo informal debido a que, en vías de una mayor competencia, se produce una carrera por reducir costos, lo que podría derivar en una pérdida de protección social a los trabajadores, en especial si no existe una reforma laboral que los beneficie.

La investigación es relevante no sólo en el análisis de la protección social sino en el de una mayor competencia de mercado. Si bien, por un lado, México es uno de los países con mayor apertura comercial en el mundo, también, al compararse con países de la OCDE para los que existen indicadores comparables, es uno de los más retrasados en términos de competencia de mercado, y no ha experimentado avances significativos a través de los años para mejorar estos indicadores (Conway, et al., 2005). Por otra parte existen pocos estudios sobre este tema de competencia, entre ellos el realizado a nivel de varios países por Karlinger (2009) donde encuentra que mayor competencia conlleva mayor economía informal en países con baja recaudación y corrupción, así como el análisis que realiza Guadalupe (2007) para el Reino Unido, donde se señala que existen efec- 
tos positivos de mayor competencia sobre salarios. Para México no existen estudios que relacionen mercado de trabajo con competencia.

El objetivo del presente artículo es analizar el efecto de la competencia de mercado en aquellos empleos no cubiertos por la seguridad social como forma de protección laboral (a los que llamamos informales) en el sector manufacturero nacional. Si bien ésta no es la única definición de informalidad es la más directa en términos de medición de cumplimiento de regulaciones laborales y de cobertura social de un trabajador, ya que las encuestas de empleo contienen la pregunta de si cuenta con algún tipo de seguridad social por el trabajo que realiza.

Para ello utilizamos microdatos provenientes de la Encuesta Nacional de Empleo de 1987 a 2004 y también datos de competencia de mercados calculados a partir de las encuestas industriales para México. Se llevó a cabo un método cuantitativo en dos etapas: en la primera, calculamos las probabilidades de que los trabajadores sean informales en un sector industrial determinado, lo cual fue controlado por características individuales y del hogar; en la segunda etapa usamos los resultados de estos cálculos y creamos un panel de datos en el que determinamos el efecto de la competencia de mercado por industria y por otros factores. Los resultados muestran que, en el contexto del mercado laboral mexicano, una mayor competencia de mercado en productos del sector manufacturero conlleva un aumento en la informalidad y falta de protección en seguridad social en ese sector.

El artículo está estructurado de la siguiente forma: la sección dos presenta la literatura existente sobre competencia y mercado de trabajo, en sus efectos tanto generales como en protección social; la sección tres introduce el estado de la competencia de mercado y del mercado de trabajo en México; la cuatro presenta los modelos empíricos a utilizar en sus dos etapas. Los resultados se presentan en la sección cinco y, finalmente, se delinean las conclusiones del estudio.

\section{Marco teórico}

La teoría económica predice que, ceteris paribus, los precios deben decrecer y la eficiencia incrementarse debido a la competencia, llevando a la idea de que mayor competencia en los mercados de bienes y servicios afecta potencialmente los mercados laborales (Blanchflower y Machin, 1996). De acuerdo con Nickell (1999) hay tres principales mecanismos a través de los cuales la competencia en los mercados de bienes podría incidir en los mercados laborales. Primero: una mayor competencia en el mercado de bienes y servicios conduce a una mayor producción, y en consecuencia a una mayor demanda laboral. Esto ocurre en tanto el 
margen de rentabilidad de las industrias que detentaban mayor poder de mercado se reduce, incrementando la demanda laboral a cualquier nivel salarial. Segundo, la elasticidad de la oferta laboral se hace más pequeña en tanto la competencia se incrementa, y en consecuencia hay una reducción del salario real de negociación. Tercero, la reducción en la elasticidad de demanda de trabajo conduce a una mayor captura de ganancias por aquellos que ya están dentro del mercado laboral, lo cual tiene una incidencia en los trabajadores permanentes dado un cierto nivel salarial.

Otros estudios se han enfocado en la regulación del mercado de bienes sobre los salarios y el empleo. Autores como Griffith et al. (2006), Jean y Nicoletti (2002), Abowd y Lemieux (1993), Blanchflower y Machin (1996), Nickell et al. (1994) y Guadalupe (2007), entre otros, han hallado efectos positivos en los salarios de la competencia de los mercados en países desarrollados. En general estos estudios encuentran un vínculo entre salarios reales y competencia. Para México, Rodríguez et al. (2009) encuentran que hay un premio salarial para los mayor educados, derivado de mayor competencia de mercado en productos, sugiriéndose un proceso de sesgo tecnológico hacia los trabajadores de mayores habilidades.

Sin embargo, pocos estudios se enfocan en la protección laboral de los trabajadores bajo las condiciones de competencia de mercado en productos. Al asumir un sistema de competencia perfecta, Díaz y Snower (1996) muestran que con fluctuaciones macroeconómicas temporales y negociación salarial bajo condiciones de moderado poder sindical, un fuerte vaivén derivado de un bajo costo de despidos conduce a menores tasas de empleo. SaintPaul (1995) y Fella (2000) también encuentran que bajo condiciones de competencia perfecta los costos de despido reducen la destrucción de empleos e inclusive puede llevar a la creación de puestos y a la eficiencia, aunque esta misma severidad de los costos de despido demasiado altos reducen la eficiencia.

Sin embargo, dado que las condiciones de competencia perfecta son un tanto difíciles de obtener, otros autores han analizado la relación entre competencia imperfecta y el mercado de trabajo. En este sentido, Amable y Gatti (2004) encontraron que la mayor competencia económica incide en mayores tasas de separación laboral, pero también incrementa la probabilidad de encontrar un trabajo si se está desempleado mientras la demanda esté en expansión. En este modelo el incremento de la competencia desplaza hacia arriba la curva de demanda laboral, incrementando el empleo agregado. No obstante, los subsecuentes incrementos del ingreso real de los trabajadores, derivados de una mayor competencia, generan presiones salariales y un impacto negativo en el empleo agregado, siendo este impacto mucho mayor que el del paso anterior, lo que sugiere que cualquier mecanismo destinado a reducir el impacto de estos incrementos 
termina acentuando la situación. Amable y Gatti (2006) continúan bajo los mismos supuestos, sugiriendo que los costos de despido reducen las tasas de despido. Esto es que a mayores costos de despido la mayor competencia deriva en un resultado positivo en términos de empleo. Los autores también proponen que hay complementariedad entre las políticas que promueven la competencia y las de protección laboral, siendo entonces que la recomendación de política consista en sugerir que la apertura comercial esté acompañada de una política de protección laboral.

En un argumento similar, enfocado en la protección laboral, una línea de razonamiento estándar es que las empresas formales buscan reducir costos cuando se enfrentan a mayores condiciones de competencia y buscan reducir costos eliminando los beneficios de sus trabajadores, por lo tanto reemplazan a empleados formales con otros que tienen menores o ningún beneficio laboral como la seguridad social; o también recortan trabajadores que posteriormente estarán buscando trabajo en la informalidad. Sin embargo, este enfoque no explica por qué las empresas no han incrementado su demanda de trabajo informal, si lo que buscan es reducir sus costos al máximo para poder competir (Goldberg y Pavcnik, 2003).

Goldberg y Pavcnik (2003) también delinearon un modelo de informalidad creciente bajo condiciones de competencia por apertura comercial que puede adaptarse a la competencia en el mercado de bienes y que es consistente con el modelo de Amable y Gatti (2004), que a su vez está basado en Saint-Paul (1996). Al asumir incertidumbre en la demanda, las empresas contratan dos grupos de trabajadores: un grupo son los formales, aquéllos que se encuentran protegidos por la legislación al mercado laboral, en la que un despido no es fácil, salvo en los casos en los que se reúne una gran cantidad de evidencia sustantiva, por lo que sus actividades no son monitoreadas al resultar sustancialmente costoso; el segundo grupo es el de los trabajadores informales, los que no están protegidos por la legislación laboral y pueden ser monitoreados a un costo constante, así como fácilmente despedidos sin justificación ni pago por liquidación.

En estos casos, los modelos asumen que la diferencia en los costos de monitoreo se deriva de las regulaciones en el mercado laboral. Las empresas encuentran óptimo contratar al mismo tiempo trabajadores formales e informales, aunque dados los salarios de eficiencia de los empleados formales éstos no encuentran incentivos para realizar labores de tortuguismo. Los precios son conocidos al final de cada periodo y el nivel de empleo también es conocido con anticipación. La competencia introduce un choque con impacto negativo en los precios y ello conduce a una baja en el nivel óptimo de empleados formales, asimismo con una regulación laboral estricta, se produce una importante reubicación de trabajadores del 
sector formal al informal. En el presente artículo seguiremos este argumento y empíricamente trataremos de determinar si la competencia de mercado ha afectado en algún grado el nivel de informalidad dentro del sector manufacturero en México, ya que al tratar de reducir costos es probable que traten de evadir algunas regulaciones laborales, como las de seguridad social, que llegan a implicar hasta $60 \%$ adicional al salario, de forma que puedan seguir produciendo en el mercado de bienes.

\section{Competencia de mercado en productos y mercado laboral en México}

A pesar de que México es uno de los países con una mayor apertura comercial, el país se ubica en la lista de los más restrictivos si consideramos la regulación de la competencia del mercado de bienes dentro de la Organización para la Cooperación y Desarrollo Económico (OCDE), como nos muestra el reporte de ese organismo elaborado por Conway et al. (2005). Si bien el país ha experimentado una mejora en este índice de regulación entre 1998 y 2003, el avance no es significativo, como se muestra en la gráfica I. El reporte indica que aunque algunas reformas se han llevado a cabo, éstas no son suficientes aún para cerrar la brecha con los demás países, los cuales también han reformado sus sistemas regulatorios. Además, el reporte mencionado vincula a esta regulación de competencia con la del mercado laboral, para la cual México también queda posicionado entre los países con una regulación muy restrictiva dentro de la muestra de los países miembros de la OCDE. En consecuencia, se tienen mayores costos para cumplir con las regulaciones para contratar y despedir trabajadores, así como para mantener a un trabajador en el sector formal. Despedir a un empleado en México sólo puede ocurrir bajo muy estrictas y especiales circunstancias, lo que hace aumentar los costos del monitoreo de los empleados formales. ${ }^{2}$ Cuando las regulaciones laborales se cumplen a cabalidad pueden llegar a representar 50 o $60 \%$ de las utilidades de las empresas (Elizondo, 1992).

Con respecto a las reformas laborales, México aún carece de una bien coordinada en esta área. Desde hace años, el Banco Mundial (2001) sugirió modificar las leyes laborales con el fin de minimizar las barreras y que las empresas puedan ajustar con mayor agilidad y a la vez encontrar mejores trabajadores para cada caso en el mercado laboral, alinear implícita y explícitamente los costos laborales con el valor que los trabaja-

${ }^{2}$ El Banco Mundial (2001) ha señalado anteriormente que el sistema de beneficios para el sector formal mexicano es costoso, distorsiona la asignación del factor trabajo, disminuye la competitividad, y pobremente sirve a los trabajadores. Adicional a ello, el sistema tributario altera la asignación de recursos, incrementa los costos laborales y desincentiva la creación de empleos formales. 


\section{Gráfica I}
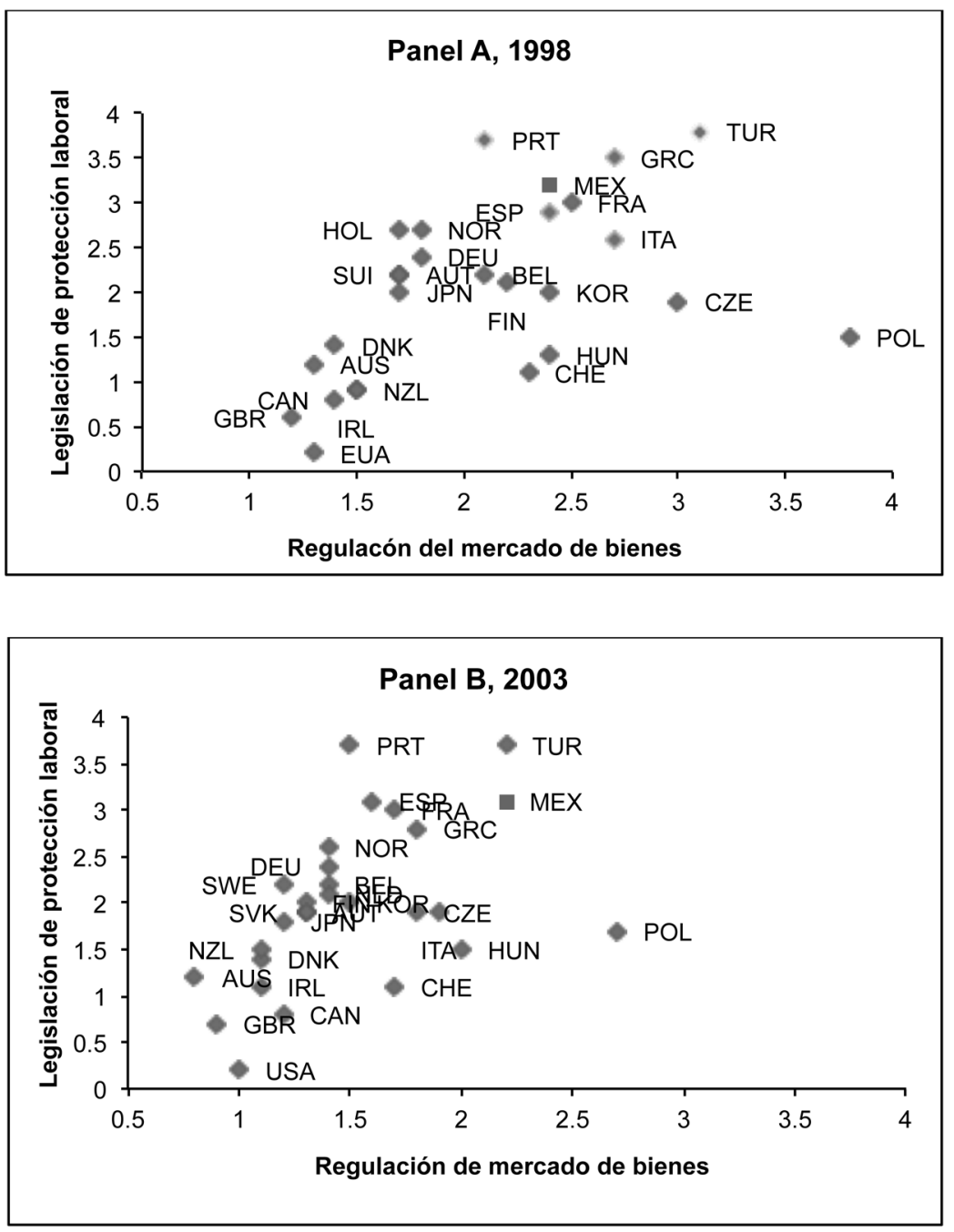

Fuente: Conway et.al. (2005).

dores le dan a aquellos beneficios, así como mantener la flexibilidad salarial en el mediano plazo. Al respecto se ha discutido una reforma laboral amplia en los últimos años, que sigue pendiente en el legislativo, pero esta reforma no desliga el trabajo formal del empleo ni tampoco busca incidir en una reducción en costos laborales. El efecto que dichas reformas tendrían en los empleos formales e informales aún no es claro y continúa sin ser estudiado.

La reforma, efectivamente ejecutada, que tal vez ha sido más importante en los últimos años ha sido la reducción en las cotizaciones para 


\section{Gráfica II \\ Trabajadores con cobertura y sin cobertura en seguridad social en México}

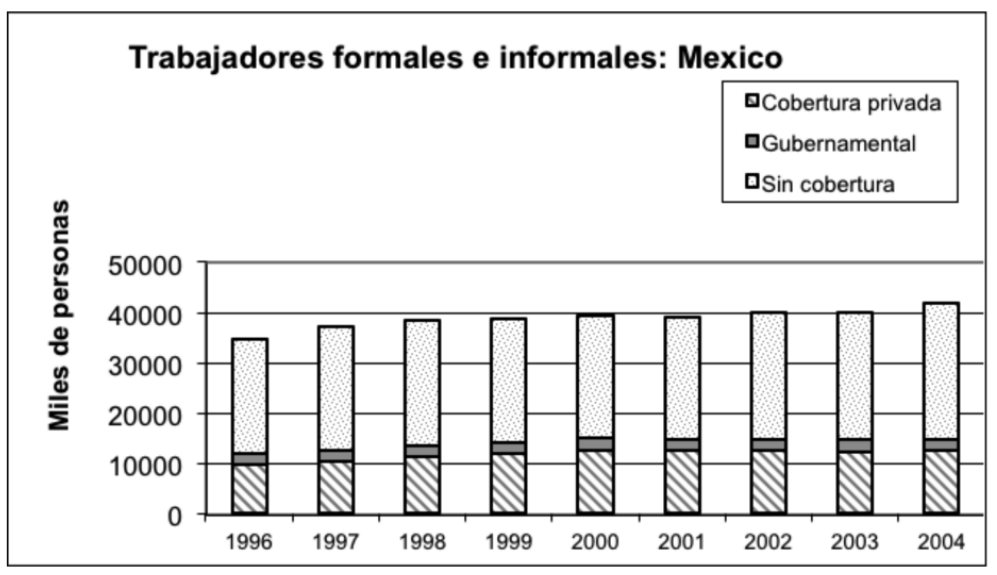

Fuente: Datos del IMSS (2007), Issste (2007), INEGI (2007) y Conapo (2007) en cada uno de los rubros incluidos.

seguridad social privada (IMSs) y el cambio al sistema de pensiones de cuentas individualizadas que comenzó en 1997. En concordancia, uno de los principales objetivos de dicha reforma fue la creación de empleos formales. Sin embargo, como se observa en la gráfica II, no hubo cambios importantes en el incremento del empleo cubierto en el sector privado, por el contrario, se observa la estabilidad del mismo en los últimos años. En su lugar el número de empleados informales ha crecido. Y aunque esta reforma ha incrementado ligeramente la valoración implícita de las cotizaciones de los trabajadores para sus beneficios de seguridad social, el incremento de los empleos formales no fue significativo como consecuencia de esta reforma (Garro et al., 2005).

Por otra parte, el tipo de contribución a la seguridad social está relacionada con niveles de ingreso laboral y a la desigualdad salarial que pueda derivarse de las cotizaciones en diferentes instituciones de seguridad social. Como se observa en la gráfica III, el salario promedio de las contribuciones al sistema de seguridad social privado (IMSs) está rezagado con respecto al de la burocracia pública (ISSSTE) y a la categoría de otros (que contienen a PEMEX y a la Secretaría de la Defensa). Los que no están protegidos tienen mayores sueldos promedio que los privados con cobertura antes de la crisis de 1995; entonces, los salarios de los no cubiertos caen en tanto la proporción de informales y se incrementan durante el 


\section{Gráfica III}

\section{Salario real promedio (pesos 2002)}

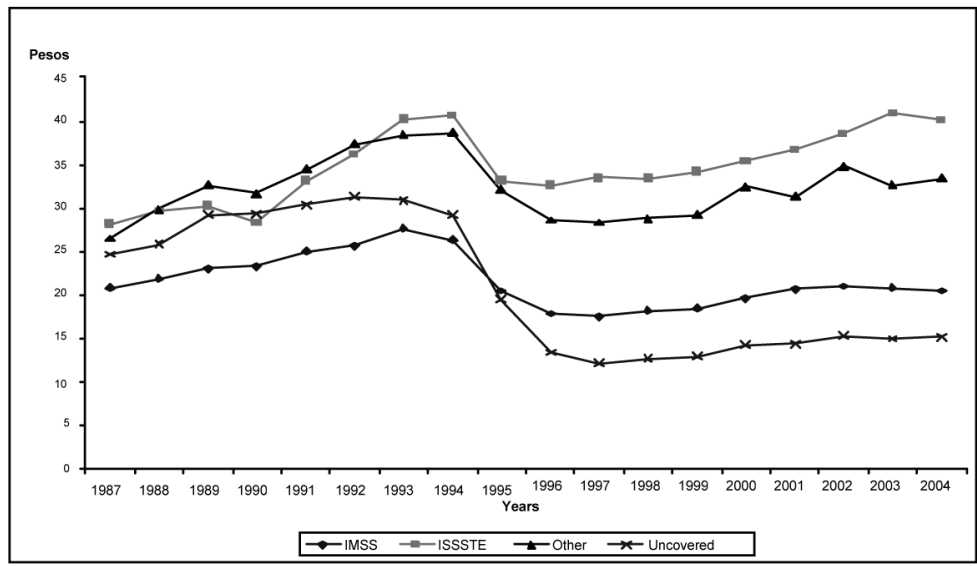

Fuente: Cálculo propio usando datos de la ENEu/T en cada uno de los años incluidos. Otros se refieren a PEMEx y a la Secretaría de la Defensa, etc.

mismo periodo. Esto podría sugerir la existencia de un salario de eficiencia para el mercado laboral mexicano. ${ }^{3}$

Algunos estudios han encontrado que previo al TLCAN la iniquidad salarial se incrementó en México a consecuencia del cambio tecnológico (Cragg y Epelbaum, 1996), mientras que el efecto post-TLC del comercio en la brecha salarial es nulo (Esquivel y Rodríguez, 2003). Otra evidencia para México muestra que los retornos por la educación decrecieron a mediados de la década del noventa y no se han recuperado a los mismos niveles, ello a consecuencia de algunos temas vinculados con la geografía del comercio, pero principalmente con factores institucionales y con el aumento de la informalidad (Rodríguez, 2005). No obstante lo anterior, no existe en la investigación un vínculo claro para la mayor competencia y sus efectos en el mercado de trabajo. Por lo tanto, el presente artículo asume la tarea de vincular la informalidad laboral con la competencia de mercado.

\section{Planteamiento empírico}

El presente estudio se basa en la metodología de dos etapas usada por Dickens y Katz (1987), Katz y Summers (1989) y Goldberg y Pavcnik (2003). En la primera etapa separamos la probabilidad específica de cada

\footnotetext{
${ }^{3}$ Maloney y Ribeiro (1999) encontraron que los salarios de eficiencia realmente existen en México en tanto las empresas pagan un salario por encima de aquel al que los mercados se satisfacen para evitar movimientos en la demanda de trabajo de la ecuación salarial.
} 
industria a la informalidad, calculando un modelo ${ }^{4}$ de probabilidad lineal para la informalidad de la siguiente manera:

$$
\mathrm{Y}_{\mathrm{ijt}}=\mathrm{H}_{\mathrm{ijt}} \beta_{\mathrm{Hi}}+\mathrm{I}_{\mathrm{ijt}}{ }^{\mathrm{ijt}} \mathrm{ip}_{\mathrm{jt}}+\varepsilon_{\mathrm{ijt}}
$$

Donde $\mathrm{Y}$ es una variable binaria que toma valores de 1 si el trabajador i se encuentra en la informalidad (no cubierto por la seguridad social) y es empleado en la industria $\mathrm{j}$ en el año t. $\mathrm{H}$ es un vector de características sociodemográficas del hogar del trabajador, I es un grupo de variables binarias por industria en la que el empleado específico es contratado; ip son los coeficientes que capturan el efecto de la probabilidad de ser informal y que no es explicado por otros factores, o diferenciales de informalidad por industria. Estos coeficientes ip se normalizan usando la metodología de Haisken y Schmidt $(1997)^{5}$ de mínimos cuadrados restringidos en dos etapas para cada año y aglutinando los errores estándar por industria. En este modelo usamos variables dicotómicas por industria al nivel de dos dígitos, que nos da aproximadamente 48 industrias para las que corremos las regresiones por cada año en forma separada para cada ańo para el periodo 1987-2004.

La muestra es para trabajadores del sector manufacturero, de 18 a 65 años de edad, que trabajen en el sector privado. Las variables a incluir en el vector $\mathrm{H}$ son dicotómicas para los niveles de edad, sexo, educación, estado civil, jefe de familia, asalariado, razones de dependencia dentro del hogar, otros miembros del hogar con seguridad social en su trabajo, tamaño de la empresa que los contrata, así como control para cada una de las nueve áreas geográficas del país.

En una segunda etapa, se hace una regresión en conjunto de los coeficientes ip normalizados con respecto al tiempo, vinculándolos con mediciones de competencia en el mercado de bienes, el modelo también captura las reformas laborales conforme la siguiente especificación:

$$
\mathrm{ip}_{\mathrm{jt}}=\mathrm{T}_{\mathrm{jt}} \beta_{\mathrm{T}}+\mathrm{D}_{\mathrm{jt}} \beta_{\mathrm{D}}+\mathrm{u}_{\mathrm{jt}}
$$

Donde ip son los coeficientes normalizados de la primera etapa. T es un vector de medidas de competencia en la industria $\mathrm{j}$ en el año t. D es un vector de variables dicotómicas por industria y por año. Para evitar el problema de autocorrelación serial usamos errores estándar del panel

${ }^{4} \mathrm{La}$ ventaja de usar este modelo es que nos permite calcular el conjunto completo de variables dicotómicas de la industria, independientemente de que la variable dependiente cambie para ese grupo.

${ }^{5}$ Estos coeficientes normalizados se interpretan como los puntos porcentuales de diferencia de ser formal o informal para un trabajador dentro de una industria, con respecto al trabajador medio en todas las industrias con características similares. 
corregido usando un rezago. Este modelo puede ser ampliado e incluir otras variables que también afecten la probabilidad de ser informal.

En la primera etapa usamos datos provenientes de la Encuesta Nacional de Empleo Urbano (ENEU) levantada por el INEgi, la cual es una encuesta trimestral que incluye información sobre las características sociodemográficas de los individuos y los hogares, así como características de los empleos, tales como salario, horas trabajadas, si el trabajo es cubierto por seguridad social, sector de actividad, prestaciones, tipo de ocupación, entre otros. Para la segunda etapa, también usamos datos de competencia en los mercados de bienes construidos a partir de las encuestas industriales del INEGI, y para la información sindical usamos información proveniente de la Encuesta Nacional de Empleo, Salarios, Tecnología y Capacitación (ENESTYC) levantada por la Secretaría del Trabajo. Las estadísticas básicas se pueden consultar en el anexo.

\section{Resultados y discusión}

\subsection{Primera etapa}

La tabla 1 presenta resultados para los años seleccionados de la primera fase del análisis, se usan microdatos provenientes de la ENEU para una muestra de trabajadores en el sector manufacturero con edades entre 18 y 65 años, urbanos, pertenecientes al sector privado, en el periodo de 1987 a $2004 .{ }^{6}$ Como puede notarse, a menor edad es menos probable que el trabajador no esté cubierto por la seguridad social o sea informal, la probabilidad se incrementa con la edad. Los coeficientes para hombres no son consistentemente significativos. La probabilidad de ser informal también decrece en razón de un mayor nivel educativo. Lo mismo para un trabajador casado, su probabilidad de ser informal es menor, lo mismo sucede con el jefe del hogar.

Los coeficientes para la variable, correspondientes a la relación de dependencia para menores de 12 años, resultan en la mayoría de los casos no significativos. Aquellos trabajadores con mayores tasas de dependencia, mayores de 65 ańos, son menos proclives a ser informales en su empleo. Los empleados de empresas medianas también tienen menos probabilidades de ser informales. Si hay otro miembro del hogar que cuente con seguridad social, entonces el trabajador también tendrá menor probabilidad formal.

Esta última variable podría indicar que si existe un miembro más dentro del hogar con cobertura de seguridad social no es un incentivo

\footnotetext{
${ }^{6}$ En 2005 se cambió la encuesta a la Encuesta Nacional de Ocupaciones y Empleo (ENOE).
} 


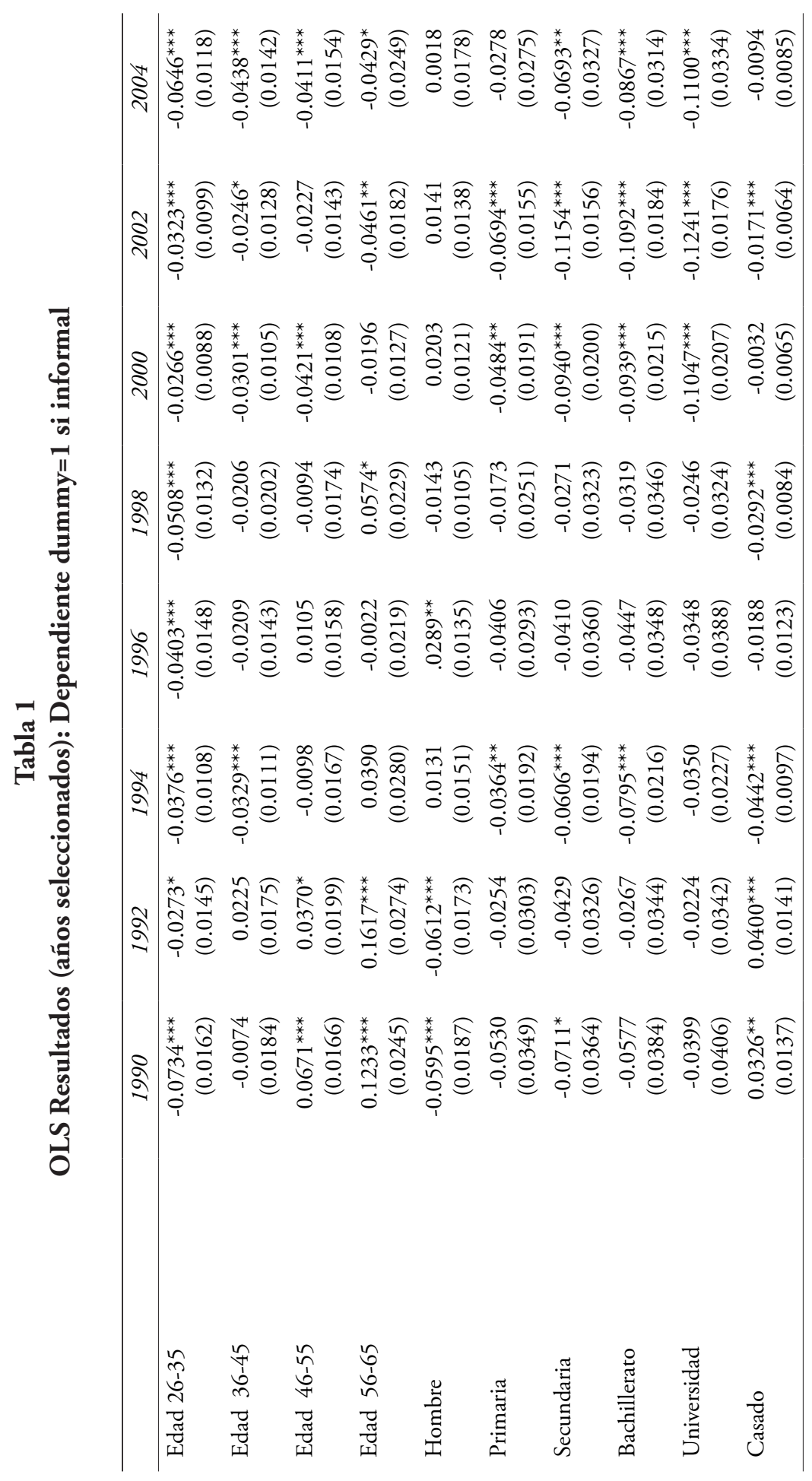




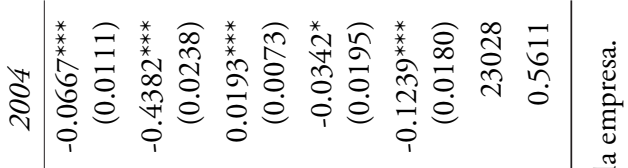

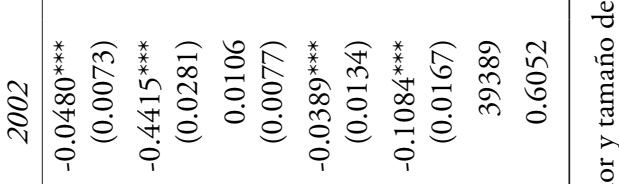

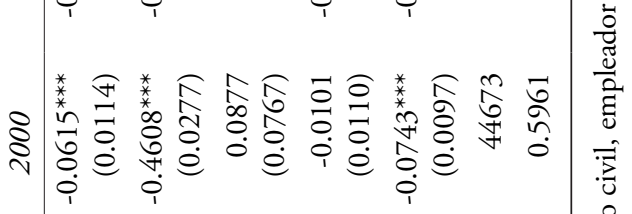

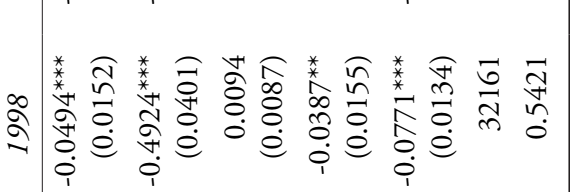

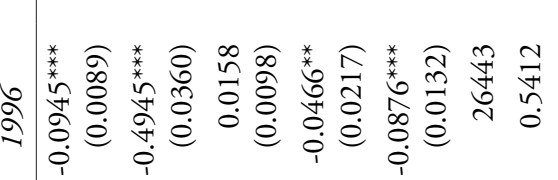

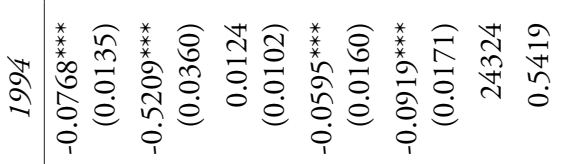

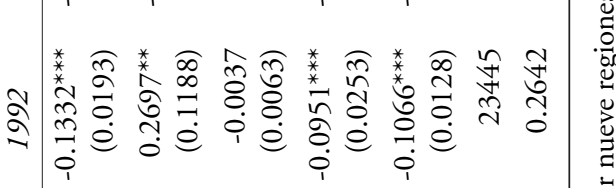

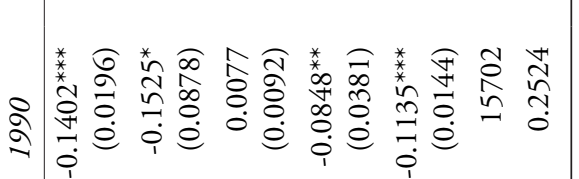

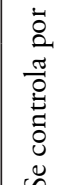

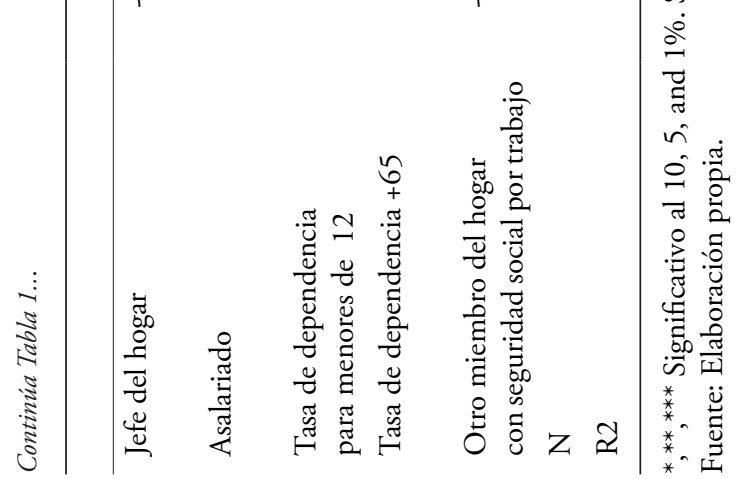


para buscar un trabajo sin cobertura de seguridad social. ${ }^{7}$ La explicación plausible sería que, como resultado de la operación de las redes de información a través de las redes de trabajo, alguien dentro del sector formal ayude o colabore a que otro miembro consiga un empleo formal.

\subsection{Segunda etapa}

En la segunda etapa del análisis usamos otra regresión en conjunto con base en los datos de diferenciales de informalidad (ip) al nivel de dos dígitos a lo largo de los años obtenidos de la primera etapa como variable dependiente; se usó, asimismo, un conjunto de variables para determinar su efecto con el procedimiento de errores estándar del panel corregido. ${ }^{8}$ Ponderamos por la inversa de los errores estándar en la primera etapa para controlar los errores de muestreo y la heterocedasticidad adicional; también incluimos variables dicotómicas por industria para capturar los efectos no observados por industria. Además, las variables dicotómicas también dan cuenta de los choques temporales durante el periodo de referencia 1987-2004.

La variable que captura la competencia es la inversa del índice CR4 (Participación de mercado de las cuatro firmas más grandes) a dos dígitos por industria calculados con Encuestas Industrial Anual de INEGI. La usamos a pesar de que Nickell (1996) sugiere que los indicadores de participación de mercado podrían no ser ideales para medir la concentración, ya que entre otras razones, no refleja la competencia exterior, tampoco la agrupación a dos dígitos representa a una industria ni a su mercado. No obstante, él sugiere que este problema se puede reducir usando datos en panel, en lugar de hacer regresiones en corte transversal. El uso de rezagos permite atenuar el problema de endogeneidad y sugiere usar un rezago de dos periodos, tal como lo hicimos en esta regresión.

La variable TLCAN es dicotómica y toma en cuenta el efecto de la entrada en vigor de Tratado de Libre Comercio de América del Norte, al respecto, es posible asumir que la apertura comercial incrementó la competencia y que, a pesar de esto, podría existir un efecto de la competencia importado de la competencia exterior (otra cosa es la competencia interna) en la que México se encuentra rezagado conforme los índices presentados en las tablas anteriores. A pesar de ello, esta variación

\footnotetext{
(2009)

${ }^{7}$ Evidencias similares se pueden hallar en Auerbach et al. (2005) y para México en Rodríguez

${ }^{8}$ Efectuamos nuestras pruebas para autocorrelación serial en el panel de datos con la prueba del Wooldridge. En todos los casos la prueba F es significativa rechazándose así la hipótesis nula de que no existe autocorrelación.
} 
que representa la entrada del TLCAN puede introducir un efecto en la competencia interna a través de la reducción de la participación de la industria del total del mercado de la misma. Por otro lado, podría estar teniendo también un efecto sobre la informalidad como una condición previa necesaria de muchos países en vías de desarrollo para poder ser competitivos, dado que muchas de sus industrias están comparativamente en desventaja, por lo tanto, nosotros incluimos esa variable dicotómica para capturar este efecto. Propiciamos que dicha variable interactuara con la variable competencia para conocer si hay un efecto diferenciado de mayor competencia, posterior a la entrada del TLCAN y, así, haya una incidencia sobre reducción de costos laborales para poder competir, reflejándose en mayor informalidad.

Adicionalmente incluimos una variable para el Índice de Penetración de Importaciones (IPR por sus siglas en inglés) calculado como:

$$
\mathrm{IPR}=\text { importaciones } / \text { (producción-exportaciones+importaciones) }
$$

En éste se captura el efecto de la competencia y puede complementar la medida de ésta tal como se mencionó anteriormente. Esta variable fue construida usando datos del Censo Industrial Anual, del Banco de México y de las bases de datos del INEGI; usamos éste índice rezagado por dos periodos al nivel de dos dígitos en industria. Esta variable también la haremos interactuar con Competencia, de forma que podamos determinar si hay un efecto diferenciado de mayor competencia y mayor índice de penetración de importanciones que acelere el proceso de reducción de costos a través de no otorgar seguridad social a sus trabajadores.

Incluimos también una medida para capturar el grado de sindicalización en cada industria, la variable Sindicatos, la cual fue calculada por la Secretaría del Trabajo de México usando las Encuestas Nacionales de Empleo, Salarios, Tecnología y Capacitación, las cuales se llevan a cabo en forma discontinua, por lo que sólo tenemos datos para los años 1995, 1999 y 2001; por lo tanto usamos el porcentaje del ańo 1995 para los años 1987-1995, el 1999 para el periodo 1996-2000, y el 2001 para el periodo 2001-2004. Esta variable ha sido interactuada con una tendencia en el tiempo (Sindicatos*Tiempo) para determinar el impacto a lo largo del tiempo de la capacidad de negociación de los sindicatos en lo que respecta a la informalidad. Como era de esperarse, ese poder de negociación puede reducir las tasas de informalidad en la industria. De acuerdo con Fairris (2003) el poder de los sindicatos mexicanos disminuyó mucho en el año 1990, así que esta variable podría llegar a resultar no significativa para determinar la informalidad. 
Otra variable considerada es la de IMss, una variable dicotómica que toma en cuenta la reforma laboral introducida que reduce los impuestos sobre nómina con la finalidad de disminuir la carga para el patrón e incrementar el número de trabajadores afiliados con un nuevo sistema de pensiones y con cuentas individualizadas, mismo que inició en 1997. Esta variable es un aproximamiento a la reforma laboral requerida para incrementar la protección laboral a través de cobertura de seguridad social. No obstante Garro et al. (2005) encontraron un impacto muy pequeño de esta reforma en los empleos formales, así que no esperamos un gran impacto de los resultados del análisis actual.

La tabla 2 muestra los resultados para la segunda etapa del modelo, en la que también se incluye un conjunto de industrias y las variables sordas de varios años en las regresiones.

La variable Competencia siempre es significativa y positiva. Por cada $1 \%$ de incremento en la competencia, hay un incremento de entre 0.41 a 0.48 puntos porcentuales en la probabilidad de convertirse en informal. El coeficiente se incrementa sólo cuando se incluye la variable del Índice de Penetración de Importaciones, pero se reduce a sus niveles previos si no se incluye en esta regresión a las dummies por industria. La variable Penetración de importaciones en las columnas de la ocho a la 10 es positiva pero sólo significativa cuando se excluye al conjunto de variables relacionadas a las dicotómicas de industria (columna 10). Además de esto, tenemos menos observaciones a consecuencia de que los datos para importaciones no están disponibles para todas las industrias. En nuestro modelo también hacemos interactuar a la variable Competencia con la variable Índice de Penetración de Importaciones para obtener el efecto de la informalidad de industrias con mayor competencia en su mercado de bienes y mayor apertura comercial, simultáneamente, aunque el resultado fue débil, con cambios en los signos de los coeficientes y sólo significativo y negativo sin las variables dicotómicas de industria pero sin tomar en cuenta los efectos no observados de la industria.

Incluimos la variable IMss, que toma el valor de 1 después de la reforma, la del sistema de seguridad social (el privado); los resultados para este coeficiente muestran que no siempre es significativo e inclusive cambia de signo. Por lo tanto es difícil obtener alguna conclusión sobre su efecto. A pesar de esto, cuando el signo negativo es significativo, sugiere un decremento de la probabilidad de la informalidad, aunque con un efecto pequeño. Garro et al. (2005) por ejemplo, estudiaron el impacto de esta reforma en el mercado laboral, encontrando que el efecto en el incremento de los trabajos formales fue mínimo, lo cual también está relacionado con la forma en que los trabajadores y empleadores 


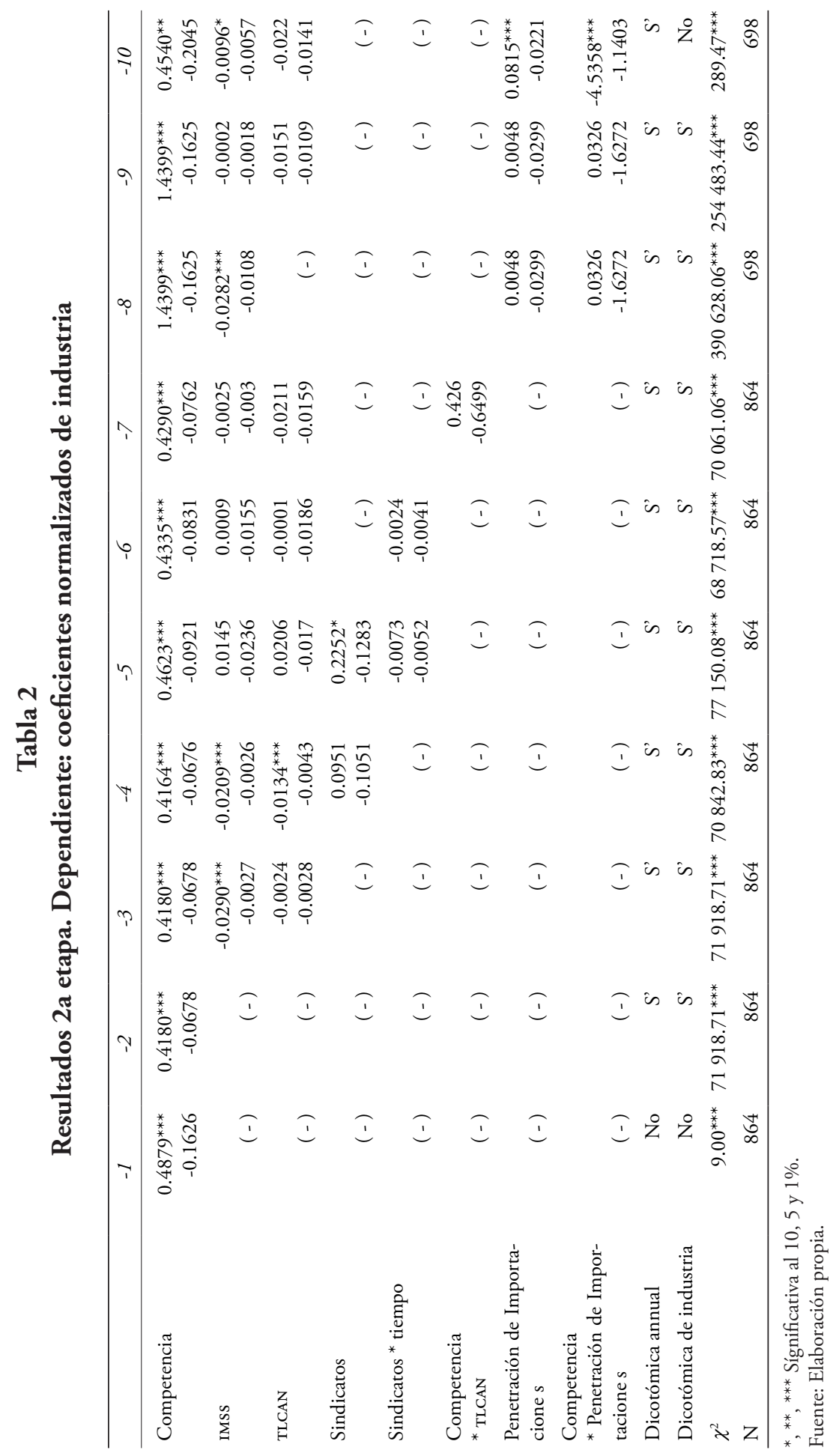


valoran los beneficios por los cuales están pagando con sus contribuciones al sistema de seguridad social.

El efecto del TLCAN es también mixto, estos coeficientes también cambian de signo y de significancia dependiendo de las variables que se hubieran incluido en la regresión, y sólo significativas cuando se incluye a los sindicatos. En el resto de los casos, no es significativo. Por último, la interacción entre Competencia y TLCAN tampoco es estadísticamente significativa.

En el caso de la variable Unión es significativa únicamente cuando se incluye la interacción Sindicatos*Tiempo ya que se vuelve negativa más no significativa. Esto muestra que a mayor poder de negociación por parte de los sindicatos a lo largo del periodo de análisis hay un efecto, no significativo, de decremento en la informalidad. Esto es consistente con los hallazgos para México, en los que el poder de los sindicatos decreció durante la década de los años noventa (Fairris, 2003).

De los resultados anteriores, parecería claro que el principal efecto de la mayor competencia en el mercado de bienes ha incrementado la probabilidad de convertirse en trabajador informal. Estos hallazgos se pueden conciliar con los resultados de los modelos de Amable y Gatti (2004 y 2006) y de Goldberg y Pavcnik (2003) en los que la competencia puede detonar un efecto negativo en la cobertura laboral si las reformas laborales no se llevan a cabo simultáneamente para proteger a los trabajadores, al extremo de que en México los trabajadores no cuentan con beneficios en caso de estar desempleados, y la legislación en la materia carece de poder vinculatorio en la mayoría de los casos. Hay razones para pensar que la industria podría haber ajustado la reducción de sus costos derivados de la mayor competencia eludiendo las regulaciones de seguridad social. Estos hallazgos sugieren que la competencia puede ser complementada con otras reformas laborales, de forma que resulte en una mejora en bienestar para todos los trabajadores.

Esto trae al debate que el marco institucional en México parece fomentar la informalidad en lugar de la creación de trabajos formales. Levy (2008) sugiere que en el actual sistema de protección y seguridad social se fuerza a los empleados y empleadores a pagar por algo que ellos valoran menos, así que ellos harán algo más allá, como evitar tal regulación, con consecuencias que afectan la productividad del trabajo. Aunado a lo anterior existen otros mecanismos que también tienden a promover la informalidad. Reportes del World Economic Forum (2007) y de la ocDE (2004) han señalado que el débil y complejo sistema de impuestos también promueve la informalidad. En Rodríguez (2010) se delinea cómo integrar la reforma laboral junto con la fiscal y de protección social, de forma que se borre la diferencia entre trabajadores formales e informales, aunque 
quedaría pendiente el cómo hacer que los previamente informales puedan ser más productivos.

\section{Conclusiones}

El objetivo de esta investigación fue analizar el efecto de la competencia de mercado en México en los empleos de los trabajadores no cubiertos en su trabajo por la seguridad social (trabajo informal). Es un tema relevante ya que durante los últimos años el número de trabajadores informales se ha incrementado en un nivel importante. Usamos datos provenientes de la Encuesta Nacional de Empleo Urbano y datos sobre competencia construidos con base en las encuestas industriales, asimismo, nos basamos en un método cuantitativo de dos etapas. En la primera calculamos las probabilidades de ser informal en un sector dado y controlando por las características individuales y de los hogares de los años 1987 al 2004. En la segunda etapa tomamos los cálculos de la primera sobre el efecto específico por industria en la probabilidad de ser informal y construimos un panel de datos para el que determinamos el efecto de la competencia de mercado en cada sector de actividad, así como otros factores y los efectos de cambios atribuibles a la entrada en vigor del TLCAN y la reforma al sistema de seguridad social, en competencia.

Los resultados muestran que una mayor competencia tiene un efecto sobre mayor informalidad, entendida como desprotección por seguridad social. De los efectos del TLCAN y la reforma al sistema de pensiones (IMSS) de 1997 es difícil dilucidar conclusiones claras. Esto señala de forma significativa la necesidad de llevar a cabo una reforma laboral amplia, donde los incentivos estén alineados con los de la economía, y que entonces el efecto de la mayor competencia se refleje en un mayor bienestar laboral. Una desregulación simple de la economía que incrementa la competencia puede incrementar la informalidad si una reforma laboral no está bien delineada y aprobada. Si consideramos que la informalidad puede tener un efecto negativo en la productividad agregada, la pérdida de bienestar de los trabajadores podría ser mayor que el beneficio obtenido por la reducción en precios, resultado de la mayor competencia global. 


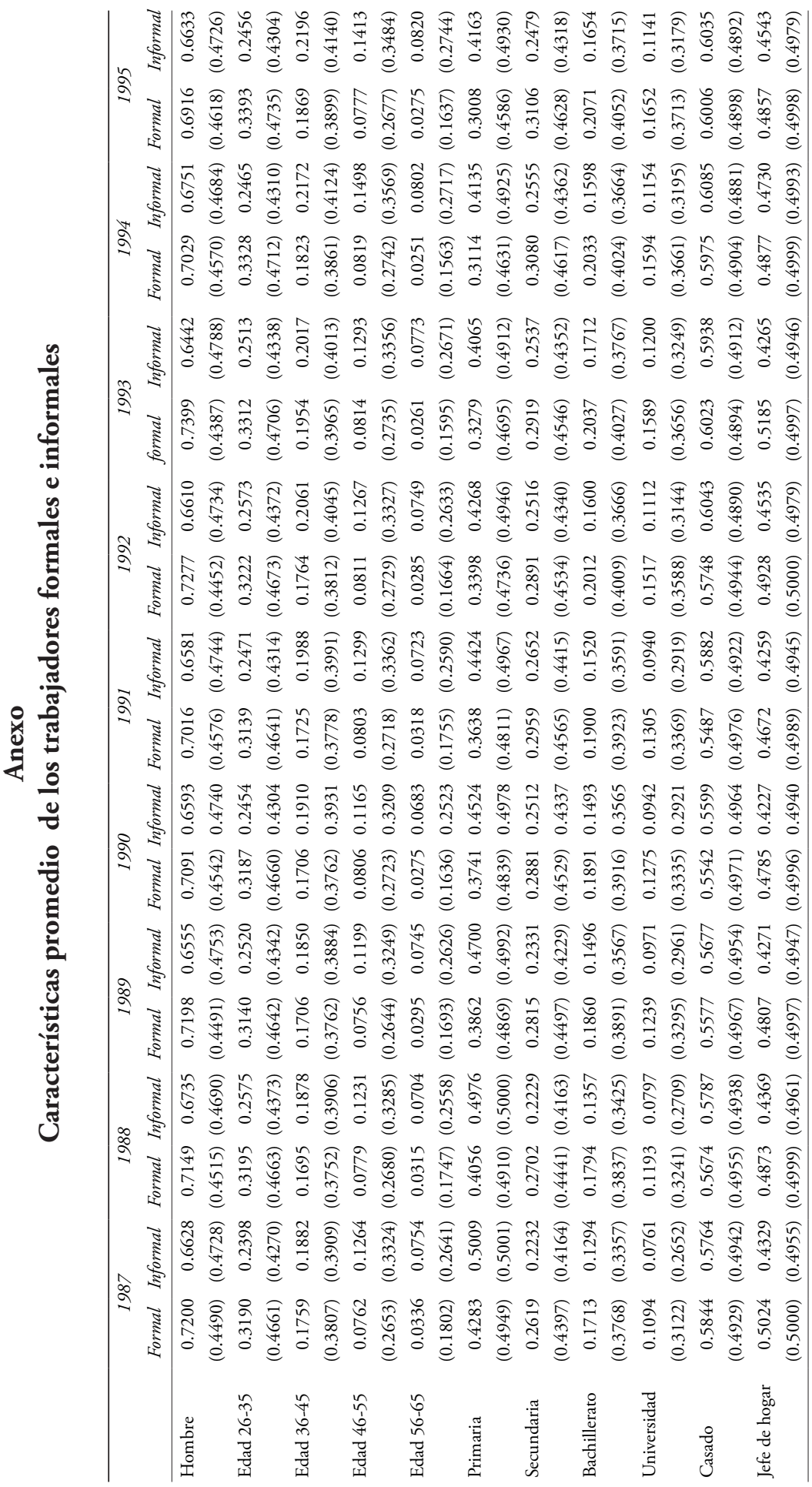




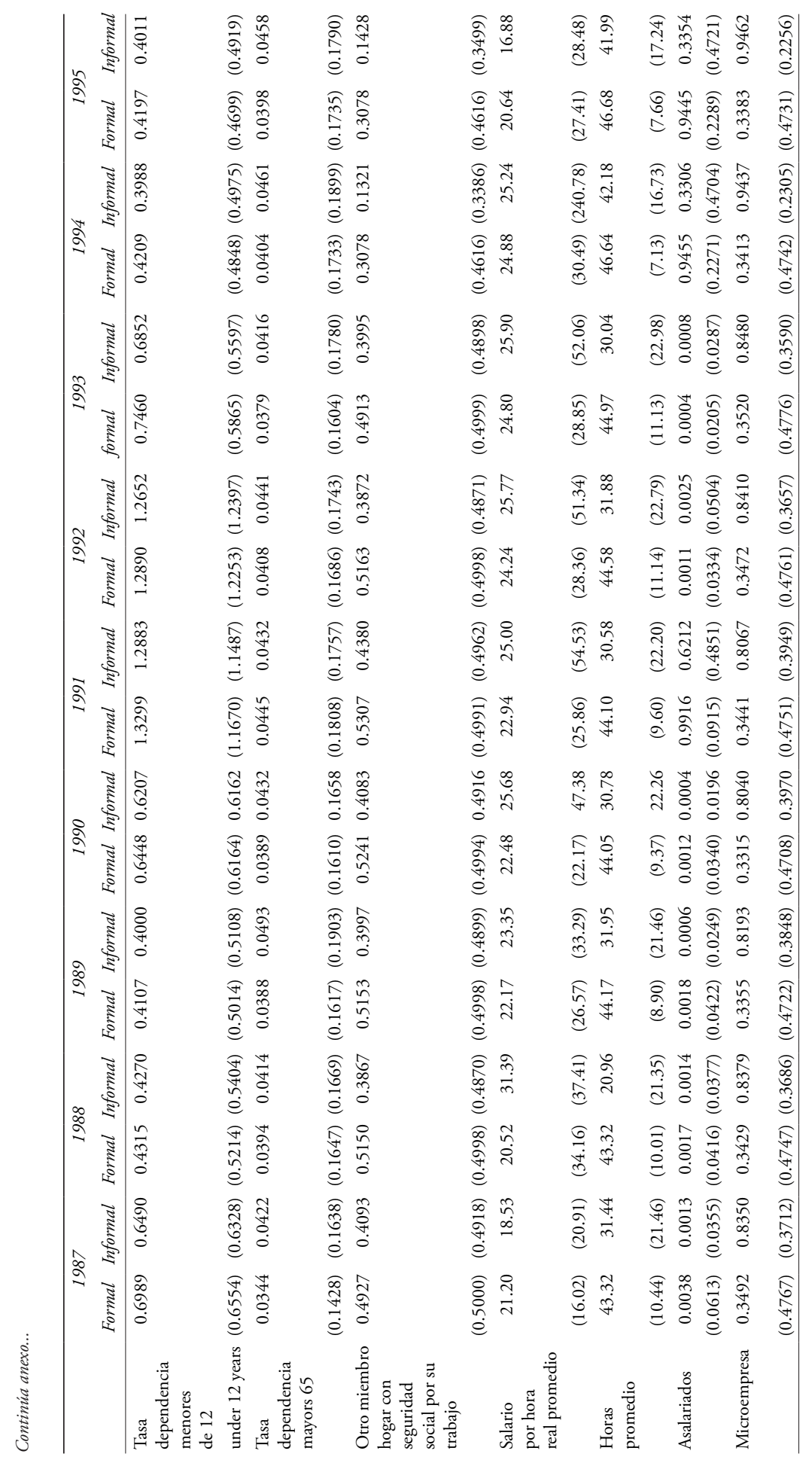




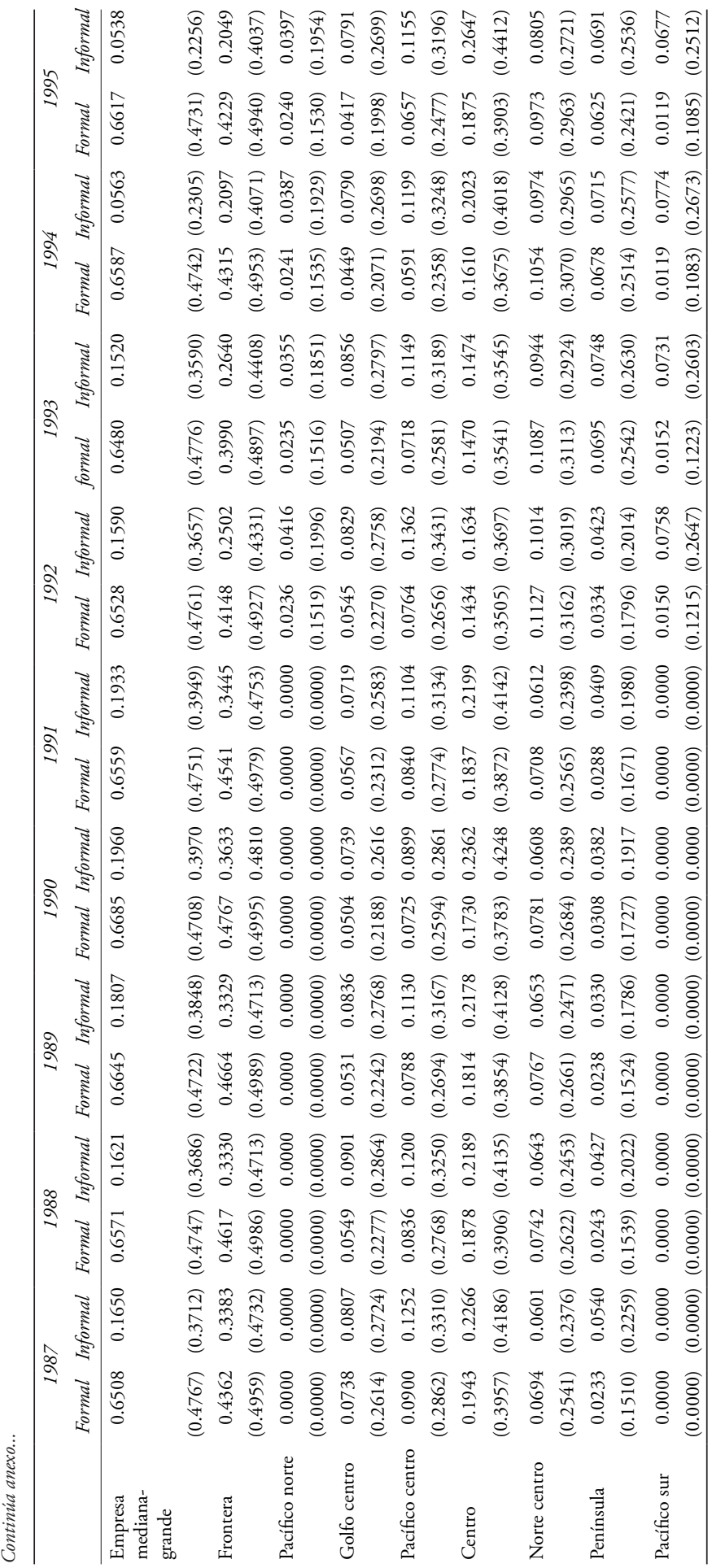




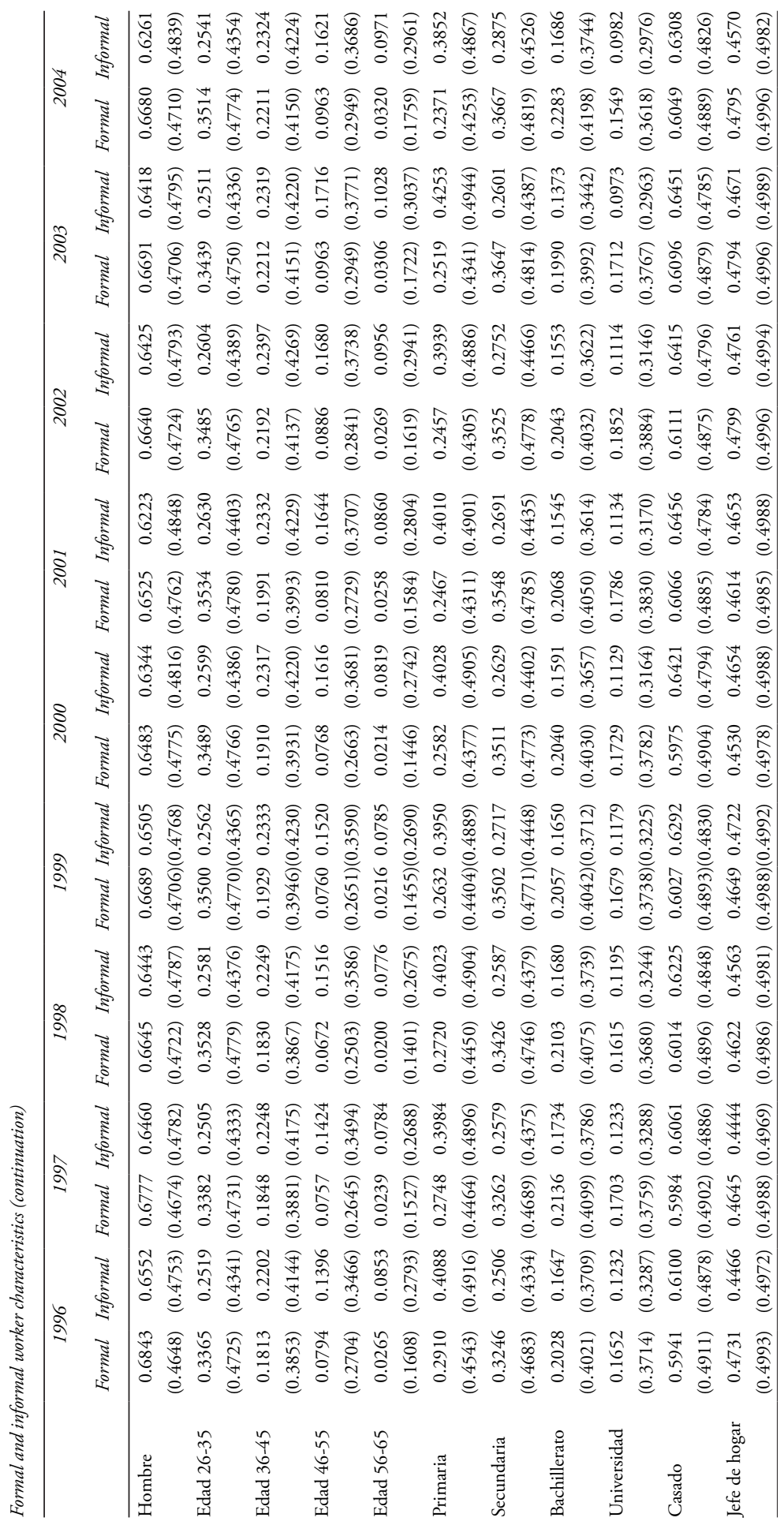




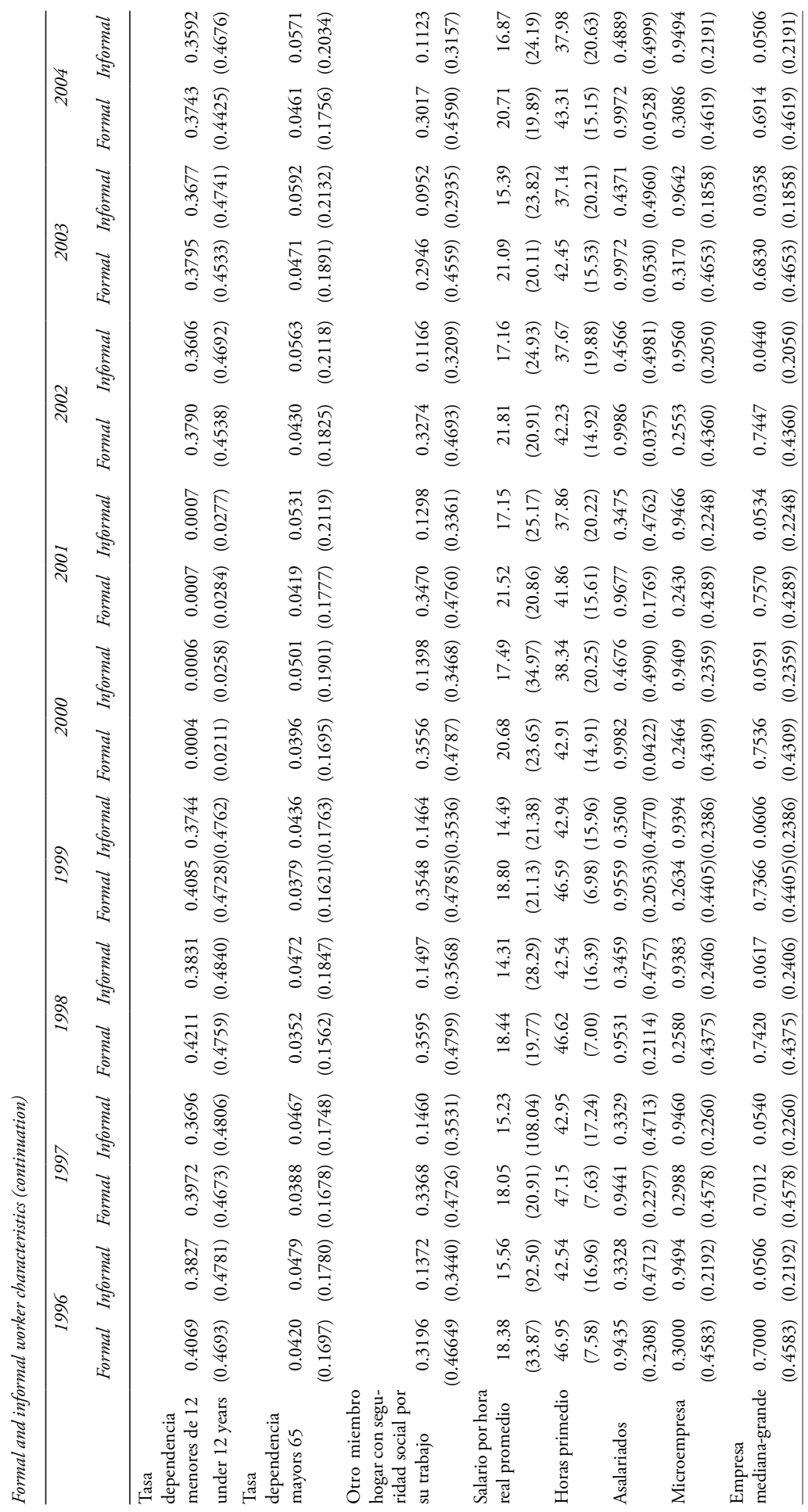




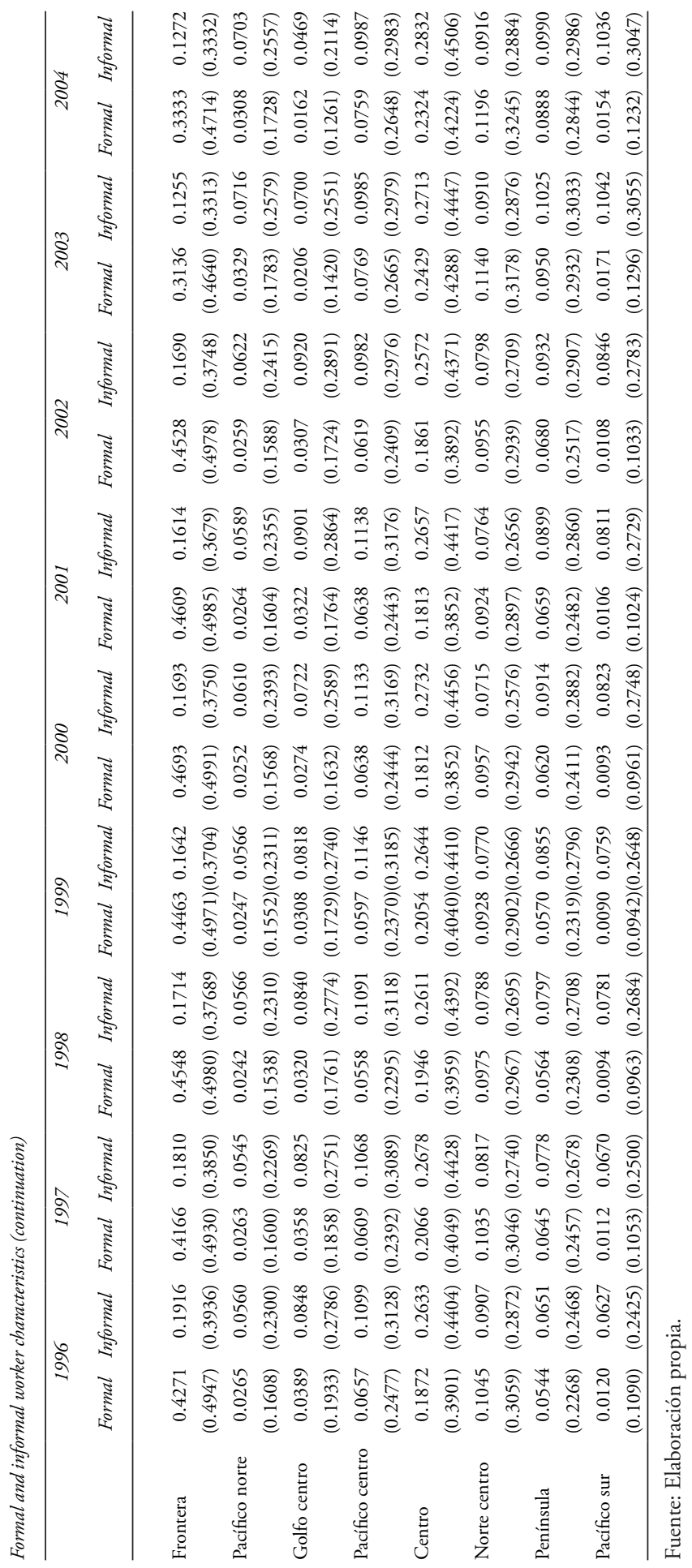




\section{Bibliografía}

Abowd, John A. y Thomas Lemieux (1993), "The effects of product market competition on collective bargaining agreements: The case of foreign competition in Canada", Quarterly Journal of Economics, 108 (4), Oxford University Press, Cambridge, pp. 983-1014.

Amable, Bruno y Donatella Gatti (2004), "Product market competition, job security, and aggregate employment", Oxford Economic Papers, 56 (4), Oxford University Press, Oxford, pp. 667-686.

Amable, Bruno y Donatella Gatti (2006), "Labor and product market reforms: A case for policy complementarity", Industrial and Corporate Change, 15 (1), Oxford University Press, Oxford, pp. 101-122.

Auerbach, Paula, Maria A. Genoni y Carmen Pagés (2005), "Social security coverage and the labor market in developing countries", IDв Working Paper núm. 447, Washington DC.

Bм (Banco Mundial) (2001), Mexico: A comprehensive development agenda for the new era, Banco Mundial, Washington DC.

Blanchflower, David y Stephen Machin (1996), "Product market competition wage and productivity: International evidence from establishment-level data", Annales D'Economie et de Statistique, 41/42, ensae, París, pp. 220-253.

Conway, Paul, Véronique Janod y Giuseppe Nicoletti (2005), "Product market regulation in OECD countries: 1998 to 2003", Working Paper 419, Economics Department, oECD, París.

Conapo (Consejo Nacional de Población) (2007), "Indicadores demográficos básicos”, www.conapo.gob.mx, consultado 2007.

Cragg, Michael y Mario Epelbaum (1996), "Why has wage dispersion grown in Mexico? Is it the incidence of reforms or the growing demand for skills?”, Journal of Development Economics, 51, Elsevier, St Louis, pp. 99-116. 
Díaz-Vázquez, M. Pilar y Dennis Snower (1996), "Employment, macroeconomic fluctuations, and job security”, Discussion Paper, 1430, CEPR, London.

Dickens, T. William y Larry Katz (1987), "Inter-industry wage differences and industry characteristics", en Kevin Lang y Jonathan Leonard (eds.), Unemployment and the structure of the labor market, Basil-Blackwell, London, pp. 48-89.

Elizondo, Néstor (1992), "Illegality in the urban informal sector of Mexico city”, en V. E. Tokman (ed.), Beyond regulation, the informal economy in Latin America, Lynne Rienner Publishers, Boulder, pp. 55-86.

Esquivel, Gerardo y José Rodríguez-López (2003), “Technology, trade and wage inequality in Mexico before and after NAFTA", Journal of Development Economics, 72, Elsevier, St Louis, pp. 543-565.

Fairris, David (2003), "Unions and wage inequality in Mexico", Industrial and Labor Relations Review, 56 (3), Cornell University, Ithaca, pp. 481-497.

Fella, Giulio (2000), "Efficiency wages and efficient redundancy pay", European Economic Review, 44 (8), Elsevier, Amsterdam, pp. 14731490.

Garro, Nora, Jorge Meléndez y Eduardo Rodríguez-Oreggia (2005), “Un modelo del mercado laboral mexicano con y sin seguridad social (IMSS)", IIDSEs Documento de Investigación, 7, UIA, México.

Griffith, Rachel, Rupert Harrison y Gareth Macartney (2006), "Product market reforms, labour market institutions and employment", IFS Working Paper W06/06, Institute for Fiscal Studies, London.

Guadalupe, María (2007), "Product market competition, returns to skills and wage inequality", Journal of Labor Economics, 25 (3), University of Chicago Press, Chicago, pp. 439-474.

Goldberg, Pinelopi y Nina Pavcnik (2003), "The response of the informal sector to trade liberalization", Journal of Development Economics, 72, Elsevier, St Louis, pp. 463-496. 
Haisken-DeNew, John y Christoph Schmidt (1997), "Interindustry and interregional wage diferentials and interpretation", The Review of Economics and Statistics, 79 (3), MIT Press Journals, Cambridge, pp. 516-521.

INEGI (Instituto Nacional de Estadística y Geografía) (2007), "Banco de Información Económica”, www.inegi.gob.mx, consultado 2007.

IMSS (Instituto Mexicano del Segro Social) (2007), "Memoria estadística", www.imss.gob.mx, consultado 2007.

Issste (Instituto de Seguridad y Servicios Sociales de los Trabajadores al Servicio del Estado) (2007), "Anuarios estadísticos", Dirección de Finanzas, www.issste.gob.mx, consultado 2007.

Jean, Sébastien y Giuseppe Nicoletti (2002), "Product market regulation and wage premia in Europe and North America: An empirical investigation", Economics Department Working Paper 318, oECD, París.

Karlinger, Liliane (2009), “The underground economy in the late 1990s: Evading taxes or evading competition?", World Development, 37 (10), Elsevier, St Louis, pp. 1600-1611.

Katz, Lawrence, y Lawrence Summers (1989), "Industry rents: Evidence and implications", Brooking Papers on Economic Activity: Microeconomics, Brookings Institution, Washington DC, pp. 209-275.

Levy, Santigo (2008), Good intentions, bad outcomes: Social policy, informality and economic growth in Mexico, Brooking Institution Press, Washington DC.

Maloney, William, y Eduardo Ribeiro (1999), "Efficiency wage and union effect in labor demand and wage structure in Mexico: An application of quantile analysis", Policy Research Working Paper 2131, World Bank, Washington DC.

Nickell, Stephen (1996), "Competition and corporate performance", The Journal of Political Economy, 100 (4), Institute of Economics and Stadistics, Oxford, pp. 724-746. 
Nickell, Stephen (1999), Product markets and labour markets, Labour Economics, 6, Elsevier Science B.v, pp. 1-20.

Nickell, Stephen, Vainiomaki, Jari y Wadhwani, Sushil (1994), "Wage and product market power", Economic, 61 (244), Wiley, London, pp. $457-473$.

ocde (Organización para la Cooperación y el Desarrollo Económicos) (2004), Employment Outlook 2004: Mexico, ocde, París.

Rodríguez-Oreggia, Eduardo (2005), "Institutions, geography and the regional development of returns to schooling in Mexico", Documento de Trabajo 8. IIDSEs/Uia, México.

Rodríguez-Oreggia, Eduardo (2009), "La dinámica comparativa del sector informal en México", en Isidro Soloaga (ed.), Sobre México: temas de economía actual, Universidad Popular Autónoma del Estado de Puebla, Puebla, pp. 167-192.

Rodríguez-Oreggia, Eduardo, Héctor Moreno y David Mulato (2009), "Has product market competition reshaped returns to schooling in Mexico?", EconoQuantum, 5 (1), Universidad de Guadalajara, Guadalajara, pp. 61-78.

Rodríguez-Oreggia, Eduardo (2010), “Informalidad y políticas públicas: El caso de México", Informalidad y Políticas Públicas en América Latina, Adenauer, SPLA, Río de Janeiro, pp. 181-194.

Saint-Paul, Gilles (1995), "Efficiency wage, commitment and hysteresis", Annales d'Economie et de Statistique, 37-38, EnSAE, París, pp. 39-53.

Saint-Paul, Gilles (1996), Dual labor markets: A macroeconomic perspectives, MIT Press, Boston.

World Economic Forum (2007), “Global competitiveness report 20062007”, WEF, Ginebra.

Recibido: 27 de febrero de 2009. Reenviado: 5 de junio de 2011. Reenviado: 19 de septiembre de 2011. Reenviado: 21 de octubre de 2011. Aceptado: 8 de noviembre de 2011. 
Eduardo Rodríguez-Oreggia. Es doctor por la London School of Economics, actualmente es director del doctorado en políticas públicas en la Escuela de Graduados en Administración Pública del ITEsm campus Estado de México. Es miembro del Sistema Nacional de Investigadores de México. Cuenta con diversas publicaciones en revistas científicas internacionales. Ganador de la Medal for Research on Development 2005, otorgada por la Global Development Network por su investigación sobre mercados laborales e instituciones en México. Ha publicado en revistas académicas internacionales como: Journal of Economic Behavior and Organization, World Development, The World Economy, Economic Geography, Public Choice, Trimestre Económico. Ha sido consultor para el Banco Mundial y para el Programa de las Naciones Unidas para el Desarrollo, así como para diversas dependencias gubernamentales.

José Martín Lima-Velázquez. Estudió la licenciatura en economía y posgrado en gestión y análisis de políticas públicas en la Universidad Iberoamericana. Se ha desempeñado como consultor externo de algunas instituciones públicas y organismos internacionales como la Comisión Nacional de los Salarios Mínimos y el Banco Mundial. Actualmente se desempeña como consultor del Consejo Nacional de Evaluación de la Política de Desarrollo Social (Coneval).

David Mulato-Martínez. Es licenciado en economía por la Universidad Iberoamericana. Tiene estudios de economía y políticas públicas en la Universidad Torcuato Di Tella en Buenos Aires, Argentina. Actualmente es asesor económico para la Comisión de Presupuesto y Cuenta Pública de la Lx Legislatura federal. Ha trabajado en la Secretaría de Desarrollo Social y la Secretaría de Medio Ambiente y Recursos Naturales. Entre sus publicaciones se encuentran: en coautoría, "Market structure: concentration and imports as determinants of industry margins", Estudios Económicos, 21 (2), El Colegio de México, México, pp. 177-202 (2006); "Ciclos de poder de mercado industrial; México 1980-1998”, Documento de Investigación IIDSES, núm. 16 Universidad Iberoamericana (2007); en coautoría, "Has product market competition reshaped returns to schooling in Mexico?”, próxima publicación en EconoQuantum, Universidad de Guadalajara. 